\title{
ASPECTOS MOTIVACIONAIS DA PROFISSÄO DOCENTE UNIVERSITÁRIA
}

\section{Bettina Steren dos Santos \\ Camila de Barros Rodenbusch \\ Denise Dalpiaz Antunes}

\section{RESUMO}

A motivação humana configura-se em processos motivacionais e são muitos os elementos em sua especificidade e particularidades, pois, perpassam a caminhada docente, entre auto-formação e formação acadêmica, iniciando-se com desejos próprios do professor. Já na práxis educativa é necessário compreender como a motivação é entendida pelo docente, na perspectiva de ajudar a desencadear os motivos intrínsecos de cada aluno. Este artigo é parte de uma pesquisa desenvolvida pelo Grupo de Pesquisa Processos Motivacionais em Contextos Educativos (PROMOT) da PUCRS. Especificamente, a intenção desse estudo é saber como os professores no Ensino Superior concebem a motivação e como ela interfere na prática pedagógica. É um estudo de caso qualitativo, com análise das falas de sete professores universitários e posterior descrição e exploração dos aspectos motivacionais com suas atuações no Ensino Superior numa Universidade Privada do RS. A partir da análise de conteúdo (Bardin, 2004), apresentam-se as categorias, a priori, Concepção de Motivação: revelaram-se diferentes entendimentos acerca da motivação. A posteriori, Trajetória Acadêmica: é um caminho longo que exige muito empenho e dedicação dos que fazem parte do mundo univeristário; História de vida e Autorealização: as vivências desde a infância embasam a formação profissional e servem de modelo para a construção das metas; Formação Pessoal e de Futuras Gerações: evidenciou-se a preocupação de tornarem-se pessoas melhores para a educação das futuras gerações.

\section{PALAVRAS-CHAVES}

Processo motivacional; Docência universitária; Prática docente

\section{ASPECTOS MOTIVACIONAIS DA PROFISSÃO DOCENTE UNIVERSITÁRIA}

\begin{abstract}
Human motivation is configured as motivational processes, affected by various factors that interfere with their specificity and peculiarities. These motivational processes permeate teacher's own path, such as selftraining and academic training, which begins with intentions and desires of each teacher, long before completing his/her undergrad courses and professional experiences. Regarding educational practices, it should be understood how motivation is understood by teachers, as it helps triggering students's intrinsic motives. This article is part of an extensive research work, which is ongoing, conducted by the Research Group Motivational Process in Educational Contexts (PROMOT) at PUCRS. The intention of this study is to find out how Higher Education professors conceive motivation and how it interferes with their teaching practice. It is a qualitative research based in case study in which the speeches of Health area professors were analyzed. The sample was composed of seven professors of a private university in RS, Brazil. To achieve the research objective the Bardin( 2004) content analysis was used. The Pre categories found were: Conception of Motivation: revealed different understandings of human motivation. Post categories were: Academic Career: it is a long path which requires much commitment and dedication of those who are part of the university world; Life history and self-fulfillment: the experiences from childhood are the foundation of training and serve as a model for the construction of goals; Concern with Personal and Professional Training of Future Generations: Adults, supposedly mature, generally are concerned in helping and being useful in relation to other individuals.
\end{abstract}

\section{KEYWORDS}

Motivational process; university teaching; teaching practice 


\section{PESQUISA \\ Área Temática: Ensino de Psicologia \& Psicologia Educacional Número Especial: Motivação}

\section{INTRODUÇÃO}

"uma mesma pessoa em situações similares pode optar por ações e metas distintas, de
acordo com o momento, dependendo de uma série de circunstâncias [...]" (HUERTAS, 2001, p. 49).

Uma caminhada docente inicia-se com intencionalidades e desejos próprios de cada professor, muito antes dos cursos de graduação e experiências profissionais e específicas de cada educador. No processo de desenvolvimento, desde a tenra infância, as primeiras características e configurações pessoais irão se internalizando pelas relações interpessoais, configurando-se em específicas aprendizagens humanas e construindo cada subjetividade do indivíduo.

Santos e Antunes (2007, p. 159) esclarecem que:

As primeiras relações familiares compreenderão as construções dos próprios ideários e dos conceitos que internalizamos da cultura. Nessas primeiras interrelações terá início a real percepção acerca de si mesmo, [...] com o nível de relações estabelecidas.

Com o amadurecimento, no início da vida adulta, cada pessoa apresenta condições intrínsecas de escolha por suas caminhadas de maneira a seguir sua profissão, por exemplo, seu ofício de professor. E, no que se refere a essa fase da vida humana, Santos e Antunes (2007, p. 160) também enfatizam que:

A vida adulta, sendo um contínuo vital, não pode ser entendida como uma fatia do todo, mas, como sendo o todo em contínua reformulação e mudança. [...] deve ser percebida tanto em sua diversidade intrínseca como em sua heterogeneidade contextual.

Nesse sentido, o início da formação acadêmica, representará a internalização de novos conceitos, novos referenciais e renonavados paradigmas educacionais. Mas, "também é necessária uma disposição para abrir-se aos demais e, desse modo [...] correr risco. Algo necessário para a criação de uma comunidade de aprendizado" (YUS, 2002, p. 237), que resulte na posibilidade de elevar o nível da qualidade de vida. 
Por isso, além da academia é necessário muito empenho, estudo e pesquisa, para que as práticas educativas representem em cada educador, com cada educando, uma educação comprometida com o desenvolvimento integral, contextualizada e construtiva ao longo de toda a vida; uma educação holística. Antunes (2007, p. 43) enfatiza "que é preciso paixão por educar, por formar seres humanos integrais, paixão pela educação”.

A partir dos saberes pessoais construídos ao longo das vivências pessoais, Hernandéz (1998, p. 11) alerta que a própria formação docente "precisa considerar que docentes não partem do zero, pois possuem uma formação e uma experiência durante a qual adquiriram crenças, teorias pedagógicas e esquemas de trabalho".

Apesar de toda a subjetividade docente, que acaba se revelando na práxis, é preciso buscar alternativas pedagógicas motivadoras para diferenciadas e significativas aprendizagens em cada processo de ensino. Tornando-se imprescindível entender o profissional que atua no campo da Educação e como esse concebe a prática docente, seus processos de ensino e de aprendizagem.

Além disso, é necessário compreender como a motivação humana é entendida pelo docente, na perspectiva de ajudar a desencadear os motivos intrínsecos de cada aluno, como parte dos processos motivacionais, em cada fase da vida ou na área de atuação do profissional. Na busca de entendimentos, evidencia-se a intenção deste estudo, pelo problema de pesquisa: como os professores no Ensino Superior concebem a motivação e como ela interfere na prática pedagógica?

Para responder ao problema de pesquisa e intencionalidades desse estudo revelase o objetivo geral da investigação: verificar os aspectos motivacionais que envolvem os professores que atuam no Ensino Superior, bem como suas interferências na prática pedagógica. 


\section{PESQUISA \\ Área Temática: Ensino de Psicologia \& Psicologia Educacional Número Especial: Motivação}

\section{ASPECTOS MOTIVACIONAIS}

A motivação humana configura-se em processos motivacionais, sendo muitos os elementos que interferem em sua especificidade e particularidades. A subjetividade de cada indivíduo o diferencia como ser humano único, por suas vivências pessoais, suas relações inter e intrapessoais, seu meio cultural e pelos seus processos de ensino e de aprendizagem durante toda a vida. Esses entendimentos também estão ressaltados nas palavras de Santos e Antunes (2007, p. 159), quando afirmam que:

A diversidade está presente em todas as instâncias de vida do ser humano. Seja pelas características pessoais que diferem de um indivíduo para outro, e ora divergem em cada fase da vida, ou pelas relações interpessoais, ressaltadas nas situações econômicas, sociais e culturais.

Dessa forma, salienta-se que a motivação é um processo intrínseco no ser humano por meio do qual as interações com a sociedade concretizam as aprendizagens sócio-culturais, sendo essas os motivos pessoais de cada sujeito. Esses são internalizados, desde a infância, mas podem ser modificados a partir de motivos extrínsecos.

Assim, o processo motivacional combina ações intrínsecas e extrínsecas, podendo-se supor que os motivos extrínsecos colaborem no desenvolvimento da motivação intrínseca, internalização particular de cada ser humano. Contudo, a motivação é um conjunto de padrões de ação que ativam o indivíduo a executar determinadas tarefas, com um componente emocional individual que se instaura a partir da própria cultura do sujeito. (SANTOS; ANTUNES; BERNARDI, 2008).

No entanto, entender o ser humano e aceitá-lo como tal, principalmente aquele que está presente em cada ambiente educativo, é antes de tudo, perceber suas diferenças, suas particularidades e as suas subjetividades, concebendo um indivíduo que está em constante desenvolvimento em cada etapa de sua vida. "A motivação do ser humano, deve ser entendida na sua integralidade, mas percebida desde a sua singularidade" (SANTOS; ANTUNES 2007, p. 159). 
Ao abordar a motivação, torna-se fundamental associá-la ao comportamento e desenvolvimento humano, como também analisar a realidade educativa na qual cada sujeito está inserido. Muitas vezes, a própria situação da sala de aula ou mesmo de um ambiente educacional, revela a falta de motivação, tanto por parte dos alunos quanto por parte dos professores/educadores.

Todavia, Huertas (2001) aponta que a grande maioria das atividades e ações cotidianas que executamos não é motivadora, sejam elas de cunho educativo ou em situações rotineiras de aprendizagens, de vida. Os desejos de aprender vão estar relacionados com os motivos intrínsecos construídos e estabelecidos ao longo das interrelações. Santos e Antunes (2007, p. 156) afirmam que o ser humano pode revelar-se

Em distintas internalizações e subjetividades ímpares, que o caracterizam e o identificam com exclusividade. Seja pelos processos motivacionais vivenciados por cada indivíduo, [...], ou pelas características individuais de cada um, o ser humano constitui-se na diversidade.

Assim, é importante que cada educador, em sua função de mediador do ensino e da aprendizagem, tenha conhecimentos teóricos e tácitos. Não somente no que diz respeito ao seu domínio específico, mas com relação aos processos motivacionais e suas potencialidades em cada fase da vida humana.

\section{PROFISSÃO DOCENTE}

Sabe-se que as aprendizagens que irão edificar o ofício de ser professor serão o resultado das relações sociais, familiares, em instituições educativas ou em ambientes culturais que o constituirão. Nóvoa (1999, p. 16), afirma que "a natureza do saber pedagógico e a relação dos professores ao saber constituem um capítulo central da história da profissão docente". Ainda assim, a prática do fazer pedagógico deve proporcionar uma crítica anterior aos saberes docentes.

Por isso, refletir com e no ato educativo, contrapondo teorias, técnicas e práticas pedagógicas, aos saberes antes fundamentados, refere-se à construção de critérios e juízos do professor em sua prática diária. Ao realizar esse percurso de ação-reflexão-ação, a prática educativa será re-significada diariamente, em busca de uma nova cultura educacional e a caminho de uma dimensão humana e social mais justa e integral. Esse processo deveria ser 
construído no dia a dia escolar, pois, os professores são sujeitos de suas vidas, a partir da própria leitura de vida. A experiência vivida salienta Tardif (2002), é a base das ações pedagógicas do professor.

Nisso tudo, afirma-se que a práxis dos educadores é reveladora das competências profissionais construídas em sua própria vida, eles "copiam” das experiências discentes todo o seu fazer pedagógico. O tempo da vida anterior à vida profissional constitui-se a base para o ofício de professor, mas não determina a sua práxis; essa se edifica pelos saberes construídos em sua própria carreira. Nesse sentido, poderia se comparar à fase inicial da carreira de professor com a infância de uma pessoa, pois nesse momento de vida o sujeito vivencia momentos que serão representativos e de fundamental importância para sua vida adulta. Esse profissional poderá, neste período, absorver verdades absolutas que irão compor sua rotina e serão evidenciadas no dia a dia educativo, sejam estas verdades positivas ou negativas para sua trajetória profissional.

Os tempos de transformações, de mudanças de paradigmas, reestruturações sociais refletem-se diretamente no docente. Antes, ele era detentor do conhecimento, professava um saber dito único, com alunos homogeneizados pela própria seleção social. Atualmente, ainda responsável pelo ato educativo, o professor é o mediador do conhecimento, aquele que deve oportunizar o aprendizado e, além de perceber e acolher a heterogeneidade deve atender as necessidades individuais, oportunizar e promover o aprendizado a todos.

A construção histórica da educação remonta no social, a imagem do professor como transmissor e reprodutor de conteúdos e componentes curriculares. Assim, a figura do educador sempre ocupou um papel central na educação institucionalizada, porém, muitas são as outras responsabilidades que o social vem apontando, num contexto cultural em que os cuidadores não mais abarcam as necessidades primeiras da educação moral. Para Esteve (1999a, p. 100) "há um autêntico processo histórico de aumento das exigências que se fazem ao professor".

No cotidiano dos docentes, pode-se observar uma intensidade de atividades, sobrecarga de tarefas, muitas leituras, preparação de aulas, correção de trabalhos e provas e muitas outras ativividades que fogem do cotidiano escolar. No caso de professores 
universitários, além dessas exigências, acrescentam-se outras atividades como: participação em comissões, consultorias, pressão institucional para publicações e pesquisas, aprendizagem de novos recursos tecnológicos, submissão a normas e regras técnicas da própria instituição de ensino, o que leva, na grande maioria das vezes, a uma rotina profissional exaustiva, associada às demandas da vida pessoal.

Além disso, esse docente universitário passa por diferentes mudanças e transformações dentro das instituições, assumindo novos cargos e funções, se envolvendo diretamente com questões administrativas e burocráticas. Essas transformações, segundo Esteve (1999b, p.31) "supõem um profundo e exigente desafio pessoal para os professores que se propõem a responder às novas expectativas projetadas sobre eles".

Para o mesmo autor, assumir essas novas funções que o contexto determina, exige muito controle, equilíbrio e supõe o domínio de uma série de habilidades pessoais que não podem ser reduzidas ao âmbito da apropriação do conhecimento.

Nesse processo, as tensões provocadas nos professores, quando se deparam com a necessidade de adaptações a mudanças em um período curto de tempo, são como se ele estivesse sendo tirado de um meio cultural conhecido, em que se desenvolveu, e colocado em um meio distinto, sem esperança de voltar à antiga paisagem social (ESTEVE, 1999b).

Nessa perspectiva convém que os docentes tenham consciência de seu papel de mediador nas inter-relações, priorizando a afetividade entre os sujeitos participantes do processo educativo. Ratifica-se nas palavras de Mosquera (1976, p. 23): "A vida daquele que compreende torna-se extraordinariamente interessante e intensa. Todo instante está rodeado de uma magia que convida a meditação. Toda relação com alguém se torna extremamente produtiva e dirigida ao ser".

Para tanto, o educador deve ser portador de um olhar humanista. Suas práticas educativas diárias devem ter gosto de vida; proposta de vida mais digna, mais saudável e mais humana. Só assim, a práxis docente representará uma identidade percebida pelos alunos, num caminho de construção de saberes, constituindo-o em sua carreira profissional e vida pessoal. 


\section{PESQUISA \\ Área Temática: Ensino de Psicologia \& Psicologia Educacional Número Especial: Motivação}

\section{PESQUISA}

Este artigo é parte de um trabalho de pesquisa, que ainda está em andamento, realizado pelo Grupo de Pesquisa Processos Motivacionais em Contextos Educativos (PROMOT) da PUCRS. Configura-se, dentro do paradigma naturalista, como um estudo de caso, no qual são analisadas as falas de professores universitários da área da saúde, de forma a descrever e explorar os aspectos motivacionais relacionados com a prática docente.

A escolha dos sujeitos para esse estudo investigativo apontou para professores atuantes no Ensino Superior com regime de dedicação exclusiva, de uma Universidade Privada no estado do Rio Grande do Sul.

Para atender os objetivos dessa investigação qualitativa, foi utilizado, até o momento, como instrumento para a coleta de dados, um Roteiro de Entrevista para professores com perguntas de respostas abertas, para guiar o pesquisador na caracterização do grupo de sujeitos e na inferência das possíveis categorias. Salienta-se também, que as entrevistas, até aqui realizadas foram gravadas e, transcritas na íntegra para apreciação dos próprios professores para a devida validação.

Toda a proposta de estudo, até aqui apresentada, teve início através do contato com a Universidade e com a direção da Faculdade, para a autorização da pesquisa na instituição. No primeiro encontro com cada professor, foram apresentados e esclarecidos os objetivos e os instrumentos da pesquisa, assim como, foi recolhida a assinatura no Termo de Consentimento Livre e Esclarecido. A partir desses primeiros contatos deu-se o início, efetivamente, ao processo de pesquisa.

Até o momento a coleta dos dados foi realizada com um curso da área da saúde, onde sete professores foram entrevistados. Aqui, os mesmos serão identificados como PA, PB, PC, PD, PE, PF e PG para facilitar o entendimento do leitor. Desses, cinco possuem doutorado e todos têm curso de especialização e mestrado. Quanto ao ano em que os docentes iniciaram sua prática no Ensino Superior, há uma diversidade. Por exemplo, PG tem mais tempo de docência no Ensino Superior, e PE tem menos tempo, numa variação de sete anos. 
A análise das respostas dessas entrevistas foi realizada através da técnica de análise de conteúdo de Bardin (2004), identificando possíveis categorias e reflexões para a construção do texto final aqui apresentado.

Apresentam-se a seguir, as categorias encontradas:

\section{Concepção de Motivação}

Os dados obtidos revelaram diferentes entendimentos acerca da motivação. Talvez, conceituações construídas na prática pedagógica diária, no desenvolvimento como pessoa humana, ou mesmo, por entendimentos adquiridos no senso comum da cultura em que estão inseridos.

Quando perguntados sobre qual o entendimento de motivação, PA afirma que são "elementos que contribuem para execução de determinada tarefa, ou coisas que tu vai te envolver, então, esses elementos às vezes são de ordem interna, às vezes são de ordem externa, então, são elementos que normalmente te dão mais impulso e te proporcionam maior envolvimento com as coisas que tu estas fazendo, [...]”. PA e PD afirmam que a palavra que melhor representa motivação é "estímulo", enfatizando a idéia de condicionamento externo, ou mesmo a necessidade de recompensa para a execução de uma tarefa.

Convergindo com PA sobre a concepção de motivação, PC e PD afirmam também quanto ao motivo da ação. Ora atribuem algo interno, ora revelam algo externo para explicar motivação. PC afirma que motivação é: “[...] um motivo que gera uma ação [...], alguma coisa tua tanto interna como externa [...], que vem de dentro de ti ou alguma coisa que vem de fora que te leva a agir de uma determinada maneira [...], cada um vai ter o seu motivo, acho que daí tem as questões intrínsecas e extrínsecas.” $\mathrm{PD}$ diz: “[...] é aquilo que te estimula a fazer alguma coisa, alguma ação, alguma atitude, a forma de pensar e agir tá vinculada a uma motivação, ela tem fatores [...] bem claros extrínsecos e intrínsecos, então ela depende de mim, mas ela depende também do ambiente na qual eu tô vivendo naquele momento [...]”. 
Mesmo não tendo clareza acerca dos motivos que levam o ser humano a agir, os docentes entrevistados intuem um processo motivacional ao apontar a possibilidade de contingência externa e interna em cada ação.

Diferente dos professores anteriores, PB traz em sua concepção apresenta uma ligação entre motivação e sentimento, relatando um indicador de resultados para suas ações, através de benefícios pessoais e/ou de outro indivíduo pertencente ao seu meio social. Isso fica evidente ao afirmar que motivação "[...] é algo que te estimula a fazer alguma coisa que tu acredita, algo que te impele a fazer algo que seja em benefício próprio ou em benefício de outras pessoas, acho que é esse tipo de sentimento que é a motivação”.

Talvez um pouco discrepante das outras idéias no que se refere à concepção de motivação, PE afirma que motivação “[...] é uma questão de manter, e aí o manter são vários manteres, manter o foco, manter a vontade, manter o ideal, manter a tua filosofia de vida, [...] se eu vou pensar na minha motivação em ser professor [...]. É uma filosofia de vida, [...] eu não conseguiria ver outro motivo [...], acordar de manhã e ter a alegria em fazer o que eu faço [...] não conseguiria ter nem um terço da felicidade que eu tenho, então aqui isso pra mim é motivação, [...] muito mais numa questão emocional, [...]." Pode-se inferir que para esse sujeito a motivação é um processo, que deve ser mantido para que a pessoa possa agir.

Quando PE fala em “filosofia de vida”, ele converge com PG e PF, que trazem em suas falas, respectivamente, a "questão de vida" e "sentido da vida". Para PG "A motivação é um desenvolvimento, o que te impulsiona, e dentro dessa impulsão tem um motivo, daí vem o termo motivação né, tem que ter um motivo pra ti fazer algo [...]. No meu caso ele está ligado à questão da missão de vida, aí vem à escolha do curso, de gostar de trabalhar com gente, com pessoas enfim, então tem a ver com a missão, tem a ver com a questão da afetividade desse motivo. Tem que ter esse afeto com o motivo, que daí a gente consegue separar as questões pessoais e profissionais. A questão da realização, então a motivação ela está ligada a isso também, ao veículo de auto-realização que tu tem, de felicidade, de tu realizares algo e te sentir inteiro, [...]”. Já, PF afirma: “motivação é aquilo que dá sentido a vida da gente, o que representa o sentido da vida, é o que mantém a gente motivada, sabe são os nossos valores, praticamente eu acho que a nossa motivação, e a nossa motivação está ligada aos nossos valores”. Assim, percebe-se uma visão mais filosófica do conceito motivação 
relacionando-o com os estudos de Frankl (1991) sobre a importância do sentido da vida na nossa trajetória.

As palavras de PE, PG e PF nos remetem ao conceito de motivação de Csikszentmihalyi (2009, p. 189) que afirma ser "um estado subjetivo que as pessoas experimentam quando estão completamente envolvidas em algo".

Os professores possuem subjetividades e singularidades, o que é demonstrado através de suas falas, estando seus processos motivacionais impregnados de valores e diferentes concepções, que de diferentes mandiras interferem na sua prática docente e na sua maneira de se relacionar com seus estudantes.

\section{Trajetória Acadêmica: em busca de ser professor universitário}

A trajetória acadêmica das pessoas que fazem parte do mundo univeristário, é um caminho longo que exige muito empenho e dedicação. Cabe resaltar que dos sete professores entrevistados, cinco possuem doutorado e todos têm curso de especialização e mestrado, além da regência de classe os docentes possuem cargos na administração da Faculdade em que atuam, revelando assim uma caminhada pessoal de formação e motivação para a vida acadêmica.

Nessa segunda categoria encontram-se aspectos apresentados pelos sujeitos da pesquisa referindo-se a trajetória acadêmica, como surgiu o interesse e a busca pela docência, especificamente no ensino superior.

Os professores da pesquisa, quando questionados sobre o que os incentivou em sua trajetória de formação, até chegar à docência no ensino superior, destacam a vontade e a importância de unir a teoria a prática já conhecida. As palavras de PA ratificam: "Num primeiro momento eu nunca achei que eu teria condições de trabalhar no nível superior, porque achava que pra trabalhar em nível superior tinha que ser alguém muito estudioso, muito, hã, com uma formação em nível universitário muito consistente, e eu nunca achei que eu tivesse essa condição. "[...] sempre eu trabalhei com o ensino básico [...], mas também comecei a perceber que com a continuidade destas experiências profissionais, eu tinha criado elementos suficientes, também para passar a ser referência pra novos profissionais, então, eu 
passei a considerar que a experiência que eu tinha prática compensava de certa forma a falta de experiência que eu tinha, de conhecimentos formais, teóricos, então comecei a pensar na vida universitária, acadêmica como professor, então pra conseguir equilibrar a balança nesta questão teórico e prática eu fui fazer os meus pós-graduação, comecei então com a especialização, depois fiz a trilha acadêmica inteira [...]”.

Além da importância da relação teórico-prática, PC afirma sua vontade de sempre estar estudando, se renovando, buscando atualizações: "Ah, eu sempre queria uma situação assim, onde eu pudesse vir a unir a prática com a teoria, então na vida acadêmica isso é possível assim, a gente conseguiu unir o que a gente tem de prática com alguns aspectos teóricos, então a gente sempre vai poder ta estudando, ta lendo, ta se atualizando, ta em contato com pesquisas que era uma coisa que eu gostava bastante, então eu sempre quis [...] é que aqui na vida acadêmica eu tenho essa possibilidade de juntar as duas coisas e é por isso que eu me motivei a buscar a vida acadêmica que era pra eu puder continuar estudando", assim percebe-se uma busca constante pelo conhecimento, característica fundamental para um professor motivado pela sua função.

Já PB através de sua fala, deixa bem claro que sempre teve como objetivo se tornar professor universitário, falando um pouco da busca para alcançar esse objetivo: “[...] meu pensamento sempre foi em ser professor universitário, eu talvez hoje tivesse um pouco perdido se eu não tivesse conseguido estar na posição que eu to hoje que é de professor universitário, porque a minha cabeça sempre foi muito direcionada pro ensino universitário, eu nunca cogitei a possibilidade de dar aula em uma escola, a minha experiência escolar se limita ao estágio né, e isso foi algo que nunca passou pela minha cabeça né, eu sempre tive muito claro e talvez por isso eu tenha emendado uma especialização na graduação, no meio da especialização eu fiz prova pra mestrado, entrei no mestrado, conclui mestrado, conclui especialização, depois quando já tava mais estabilizado e pude, fui procurar o doutorado, sempre com o intuito de cada vez mais me especializar para o ensino universitário, nunca pensando de outra forma.". Podemos constatar, mais uma vez, através desse depoimento que o caminho percorrido por cada docente é subjetivo, e que se torna difícil generalizar ou apresentar dados conclusivos no que se refere à motivação docente. 
Divergindo de PB, e afirmando que as experiências práticas foram essenciais para escolha pela docência no Ensino Superior, PF afirma: "eu nunca tive assim o objetivo muito claro né, eu sempre gostei de estudar, daí eu queria aprender mais coisas, daí eu resolvi fazer um curso superior, [...] fui definindo, depois que eu experimentei, então assim trabalhei três meses [...] com crianças especiais e defini não, eu não quero trabalhar pra sempre com isso, é uma experiência enriquecedora, muito importante mas não era aquilo que eu queria, [...], no último ano do curso superior eu trabalhei num projeto de pesquisa de iniciação cientifica aonde eu trabalhei com adultos, então acho que foi dali que eu comecei a definer, é isso que eu quero, e aí eu mencionei [...] a vontade de trabalhar com aqueles que vão multiplicar o conhecimento, [...] a idéia foi fazer uma especialização, um mestrado enfim seguir este caminho, [...] foi se construindo ao longo da minha formação [...].”. Neste caso, podemos constatar que as experiências vividas pelo docente e a reflexão sobre as mesmas, levaram o docente a fazer as suas escolhas e determinar os caminhos percorridos, mostrando que em muitos casos não é uma opção previa e sim ao longo da caminhada.

Outro aspecto, referente aos entrevistados que deve ser ressaltado é a diversidade quanto ao tempo de prática docente no Ensino Superior. PG tem mais tempo de docência no Ensino Superior, afirmando que iniciou esta atividade em 1993, já PE foi o entrevistado que apresentou menos tempo, iniciando esta prática em 2005. Essa característica também deve ser considerada quando analisamos o processo motivacional dos docentes.

\section{História de vida e Autorealização}

Uma terceira categoria encontrada nos dados analisados refere-se à importância da história de vida dos docentes, ou seja, as vivências desde a infância embasam a sua formação profissional. Isso fica evidenciado na fala de PE: "Toda minha formação, desde muito pequeno, é porque eu tive a felicidade ou a facilidade, a felicidade do meu pai ser diretor de um dos clubes de Porto Alegre. A facilidade de morar na mesma quadra que o clube, então eu chegava da escola e não precisava atravessar rua nenhuma pra sair de casa e ir até o clube, na época que isso acontecia na minha infância”. 
Essas histórias de vida, não se restringem aos progenitores apenas, mas também aparecem pessoas do convívio familiar próximo, que servem de modelo para o ser humano constituir as suas metas, como explica PB: “desde muito cedo eu convivi e convivo, hoje não convivo mais porque não moramos mais juntos, mas a irmã da minha mãe morou muito tempo conosco e desde que eu tinha, sei lá 7 ou 8 anos, e a via trabalhando em casa, com muito trabalho sempre e ela era professora universitária, e eu achava, enfim acho que pela própria convivência com ela, eu comecei a achar aquela profissão interessante. O que ela falava a respeito, da relação dela com os alunos, a satisfação que ela tinha em ver os alunos aprendendo as coisas, os alunos que depois de formados muitas vezes continuavam procurando a ela e agradecendo a ela pelo tipo de estudo que tiveram, pelo tipo de envolvimento que tiveram com ela né, [...]."

Além dos familiares, destacados como modelos nessa construção, é apontado o papel de docentes ao longo da vida acadêmica, como afirma PF: "[...] foi conversando com uma professor [...] que eu disse pra ela, eu ainda não sei bem o que eu quero fazer, mas eu sei de algumas coisas que eu não quero fazer, [...], e numa conversa com essa professor, eu dizendo pra ela que eu quero trabalhar com adultos, então ela disse ah eu acho então que tu deveria seguir a carreira acadêmica [...]”. Com esse depoimento, mais uma vezprecebe-se a importância dos docentes na vida dos seus estudantes, como o vínculo estabelecido e o tipo de dialogo pode interferir nas escolhas de cada pessoa.

Ressaltamos também, através da fala de PD, aspectos que vem desde a infância e que estão associados a autorealização: "Bom, desde criança eu sempre gostei muito de dar aula, eu sempre achei que eu ia ser professorinha assim (risos) eu tinha uma coisa com a idéia de ser professor [...].” A busca pela autorealização é um dos princípios apontados por Maslow (1991) quando apresenta a hierarquia das necessidades humanas. Para o autor, chegar ao topo da pirâmide é chegar à autenticidade do ser humano ao atingir a auto-realização, ou seja, "Aquilo que os humanos podem ser, é aquilo que devem ser. Devem ser autênticos com sua própria natureza. Podemos denominar essa necessidade de auto-realização" (MASLOW, 1991, p.32). Assim, podemos perceber que pessoas que buscam a sua autorealização são mais satisfeitas com a suas vidas, segundo Maslow (1991, p. 6) “[...]o estudo da motivação deve ser, em parte, o estudo dos fins, dos desejos e das necessidades últimas do ser humano". 
Portanto, é fundamental pensar na formação docente a partir de um olhar mais amplo, considerando que ela constitui-se de diferentes aspectos da história de vida de cada indivíduo. Mosquera (1987, p. 55) delineia:

O homem se manifesta nas suas relações com seus semelhantes, não somente como um ser vivo que se empenha na sua auto-conservação e auto-realização, senão também como pessoa, isto é, como portador de valor e dignidade. Como pessoa se reflete não só na sua consciência senão também na dos seus semelhantes.

\section{Formação Pessoal e de Futuras Gerações}

Outro aspecto que ficou evidenciado nas entrevistas foi a preocupação com a educação das futuras gerações, conforme as palavras de PB quando afirma: “[...] a gente vai ficando mais velho [...], tu vai mudando a tua forma de aprender, de atender essas pessoas, de entender essas pessoas,[...], a gente tem cada vez mais alunos com idades cada vez menores, [...] pra mim são dois pontos muito claros de motivação, uma é a motivação de mostrar a importância da minha profissão para aquelas pessoas que escolheram ter também esta profissão, [...] hoje eu to formando os professores que serão os professores do meu filho. Então eu quero que estas pessoas sejam competentes, [...], eu como professor eu quero que elas saiam daqui competentes, claro que as competências serão diferentes, cada um em áreas distintas naquilo que mais gosta, mas que tenham condições de buscar o seu espaço, de buscar coisas novas que não aprenderam dentro da instituição, isso é uma coisa que me motiva bastante, [...].” Essa categoria é destacada nos estudos sobre as fases da vida adulta, quando constata-se que as pessoas mais maduras preocupam-se em ajudar os outros, enfim, na adultez tardia ou avançada, o ser humano quer empenhar-se em ajudar os outros, sendo útil para com os demais indivíduos de sua convivência. (SANTOS; ANTUNES, 2007).

Corroborando com PB, PD traz questões e preocupações referentes a formação de profissionais competentes: "[...] o que me motivou mesmo foi o fato de ter uma experiência profissional em coordenação de escola [...], ou mesmo como professora de algumas escolas $e$ ver quanto era difícil modificar o pensamento e a ação das pessoas que trabalhavam junto comigo, mesmo eu tendo um cargo de coordenação na qual eu teria uma autoridade, ou eu poderia tentar trabalhar melhor a idéia de modificar algumas ações bem práticas, eu comecei a perceber que isso era muito difícil e talvez se eu entrasse na docência, daí eu 
trabalhasse com a formação então nesse período, a formação inicial do aluno, eu teria então uma possibilidade de atuação profissional melhor, acho que isso foi o que mais me motivou, ver muita coisa errada e não conseguir fazer com que as pessoas naquele momento não, modificassem a sua ação, hoje eu até vejo como algo diferente, acho que poderia ter feito um outro trabalho com esta característica, mas foi isto que mais me motivou.”.

A questão de formação pessoal, da busca por transformar as pessoas, tornando-as pessoas melhores, também foi destacada pelos professores, PA diz que "[...] outra motivação é a possibilidade de contribuir para transformação das pessoas e da sociedade, eu acredito que a educação contribui pra essa transformação, em primeiro lugar da pessoa e conseqüentemente isso vai contribuir para a transformação social também [...]”. PD, ainda destaca o papel do professor nesta formação pessoal, afirmando que "Ser professor é ser educador, é fazer com que as pessoas, melhor, é formar pessoas, pessoas melhores tanto no âmbito pessoal como no profissional, [...]”.

Essas falas vão ao encontro de que em sua profissão, o professor professa não apenas saberes advindos das habilitações que lhe são exigidas pelas Leis de Ensino. Existe uma constante renovação na práxis de cada educador, seja pela característica de sua docência, com diferenciados alunos/sujeitos de ensino e de aprendizagem, ou pelas próprias adversidades que compõe a sua formação acadêmica e vivências sociais, ou mesmo pelo desenvolvimento humano que lhe é particular.

Cabe salientar que o educador, em qualquer instância ou representação de ensino formal, representa um ser humano ímpar em subjetividades, inter-relações e construções de saberes. Sempre em desenvolvimento, compõe em si, valores, hábitos, concepções e ações educativas que o identificam como tal.

\section{CONSIDERAÇÕES FINAIS}

Até o momento, os dados da pesquisa apontam que há uma diversidade e complexidade de concepções acerca da motivação. Mostrando ser necessário compreender como a motivação humana é entendida pelos docentes, na possibilidade de seu desenvolvimento a partir de aprendizagens eficientes e eficazes desde o início da educação formal. 
Através desse estudo, é possível verificar a preocupação dos docentes, não só em passar seus conteúdos prédeterminados, mas também com a formação pessoal e profissional. A preocupação em formar seres humanos melhores, com princípios e valores, assim como profissionais competentes e preocupados com o futuro.

Todavia, é preciso constituir-se autônomo em sua trajetória de pessoalidade, para que a sua docência também seja portadora de identidade e o torne ímpar em suas ações pedagógicas; um constante aprendiz em seus saberes. Sem deixar de perceber qual seu verdadeiro papel social, quem realmente representa frente às realizações sociais, e qual sua contribuição no dia a dia de cada educando.

Cabe salientar, que só foram apontados os dados de um curso da área da saúde, e os mesmos ainda se encontram em análise. O início da coleta em outros cursos, de diferentes áreas, está previsto para o segundo semestre de 2009.

\section{REFERÊNCIAS}

ANTUNES, D. D. Relatos significativos de professores e alunos na educação de jovens e adultos e sua auto-imagem e auto-estima. 2007. Dissertação (Mestrado em Educação) Faculdade de Educação, Pontifícia Universidade Católica do Rio Grande do Sul, Porto Alegre, 2007.

BARDIN, L. Análise de conteúdo. Lisboa: Edições 70, 1997.

CSIKSZENTMIHALYI, M. El Fluxo. In: FERNANDÉZ-ABASCAL, H. G. (Org.). Emociones positivas. Madrid: Pirâmide, 2009.

ESTEVE, J. M. Mudanças sociais e a função docente. In: NÓVOA, A. (Org.). Profissão professor. 2. ed. Porto: Porto, 1999a. 1999b.

O mal-estar docente: a sala de aula e a saúde dos professores. São Paulo: EDUSC,

FRANKL, V. E. Em busca de sentido: um psicólogo no campo de concentração. Petrópolis: Vozes, 1991

HERNÁNDEZ, F. Transgressão e mudança. Porto Alegre: Artes Médicas, 1998 
HUERTAS, J. A. Motivación: querer aprender. Buenos Aires: Aiqué, 2001

MASLOW, A. H. Motivación y personalidad. Madrid: Diaz de Santos, 1991.

MOSQUERA, J. J. M. O professor como pessoa. Porto Alegre: Sulina, 1976.

Vida adulta: personalidade e desenvolvimento. 3. ed. Porto Alegre: Sulina, 1987.

SANTOS, B. S.; ANTUNES, D. D.; BERNARDI, J. O docente e suas subjetividades nos processos motivacionais. Educação, Edipucrs, Porto Alegre, Educação, ano XXXI, v. 31, p. 46-53, 2008.

; ANTUNES, D. D. Vida adulta, processos motivacionais e diversidade. Educação, Porto Alegre, ano 30, n. 61, p. 149-164, 2007.

TARDIF, M. Saberes docentes e formação profissional. Petrópolis: Editora Vozes, 2002.

YUS, R. Educação integral: uma educação holística para o século XXI. Porto Alegre:

ARTMED, 2002. 
BETTINA STEREN DOS SANTOS

Pós-doutoranda pela Univesity of Texas at Austin, College of Education. Doutora em Psicologia Evolutiva e da Educação - Universidad de Barcelona. Professora do Programa de Pós-Graduação em Educação da Faculdade de

Educação da Pontifícia Universidade Católica do Rio Grande do Sul (PUCRS). Possui bolsa produtividade do Conselho Nacional de Desenvolvimento Científico e Tecnológico (CNPq). Coordenadora do grupo de pesquisa "Processos motivacionais em contextos educativos" (PROMOT).

E-mail: bettina@pucrs.br

CAMILA DE BARROS RODENBUSCH

Licenciada (Licenciatura Plena) em Educação Física e Mestranda em

Educação pela Pontíficia Universidade Católica do Rio Grande do Sul

(PUCRS); Pesquisadora Bolsista do Conselho Nacional de Desenvolvimento

Científico e Tecnológico (CNPq). Membro do Grupo Pesquisa em Estudos Olímpicos (GPEO/PUCRS); do Grupo de Avaliação e Pesquisa em Atividade Física (GAPAFI/PUCRS); e do Grupo Processos Motivacionais em Contextos Educativos (PROMOT/PUCRS). E-mail: milaroden@yahoo.com.br

DENISE DALPIAZ ANTUNES

Doutoranda em Educação pela Pontifícia Universidade Católica do Rio Grande do Sul (PUCRS); Mestre em Educação pela PUCRS; Especialista em

Educação Infantil; Licenciada em Educação Física; Professora da Rede Municipal de Ensino de Porto Alegre;

Professora na Especialização em Psicopedagogia - PUCRS, Pesquisadora do grupo de pesquisa "Processos motivacionais em contextos educativos"

(PROMOT).

E-mail: denise.dalpiaz@terra.com.br 